\title{
Letramento Informacional e Midiático para professores do século XXI
}

\author{
Leila Alves Medeiros Ribeiro \\ Doutoranda; Universidade de Brasília, Brasília, DF, Brasil; \\ leilagirassol@gmail.com \\ Kelley Cristine Gonçalves Dias Gasque \\ Doutora; Universidade de Brasília, Brasília, DF, Brasil; \\ kelleycristinegasque@hotmail.com
}

\begin{abstract}
Resumo: A sociedade contemporânea passa por mudanças profundas na estrutura desde que passou a agir em um sistema de rede conectado digitalmente. A transformação sistêmica alterou os processos das esferas da sociedade em especial na área da educação. Este artigo objetiva fomentar a discussão acerca da formação de professores no século XXI por meio da revisão de questões como o contexto de aprendizagem contemporâneo, a relação entre professores e mídias, bem como apresenta levantamento de pesquisas sobre o letramento informacional e midiático na formação de professores com o foco na educação básica. Os resultados mostram poucas pesquisas sobre formação docente e letramento informacional. Em sua maior parte, centram-se no bibliotecário no papel de educador ou nos professores dos cursos de graduação e pós-graduação de biblioteconomia ou tecnologias. Ao contrário, os trabalhos científicos sobre letramento midiático/digital e a formação docente no Brasil tem bastante tradição e apresenta variedade e franca ampliação.
\end{abstract}

Palavras-chave: Letramento informacional e midiático. Formação de professores. Educação XXI.

\section{Introdução}

As informações na atualidade crescem em ritmo acelerado jamais visto na história da humanidade. As pessoas estão cada vez mais imersas na cibercultura (LÉVY, 1999), o que nos torna seres $\operatorname{cíbridos}^{1}$ (SANTAELLA, 2007). As plataformas digitais apresentam informações, números de telefones, anotações, histórias e vídeos (memórias) dos indivíduos. Isso aponta novos caminhos no que concerne ao acesso, uso e compartilhamento da informação. 
Tais atividades são importantes para o sucesso acadêmico, social e profissional. Ser aprendiz vitalício e independente são premissas dos princípios da aprendizagem contemporânea. Assim, a escola mostra-se como espaço importante para o desenvolvimento nos cidadãos da capacidade de aprender a aprender. Por conseguinte, a formação do professor torna-se essencial para preparar cidadãos para atuarem de maneira responsável, ética e cidadã na sociedade em rede.

O presente artigo, parte de revisão de literatura de tese de doutorado, centra-se na discussão da formação do professor para desenvolvimento do letramento informacional e midiático na educação básica, que pode ser compreendido, grosso modo, como o processo de aprendizagem para gerar conhecimento e disseminá-lo nos vários domínios tecnológicos como forma de atuação cidadã responsável na sociedade em rede. Assim, abordam-se questões como o contexto de aprendizagem no século XXI, a formação de professores e pesquisas realizadas sobre o letramento informacional e midiático na formação de professores.

\section{Aprendizagem no século XXI e o Letramento Informacional e Midiático}

A educação encontra-se em processo de transformação, mas o ritmo da mudança parece ser mais lento do que as demandas da sociedade, que conectada em rede e potencializada pelas tecnologias da informação e da comunicação, coloca em circulação um volume de informação jamais visto antes na história da humanidade. A informação constitui-se o componente primordial do conhecimento.

Takahashi (2000, p. 45) aponta que educar na sociedade da informação significa mais do que treinar pessoas para o uso das tecnologias de informação e comunicação. Trata-se de investir na criação de competências suficientemente amplas que permite atuação efetiva no protagonismo, na produção de bens e serviços, nas tomadas de decisões fundamentadas no conhecimento. $\mathrm{O}$ foco centra-se no "aprender a aprender", de modo que os cidadãos sejam capazes de 
lidar eficaz e efetivamente com o conhecimento na contínua e acelerada transformação da base tecnológica.

$\mathrm{Na}$ atualidade, o aprendiz não é mais só o consumidor de informações e conhecimentos, agora ele também cria, inova, remixa, produz novas informações e conhecimentos na inteligência coletiva (LÉVY, 1999). Tudo isso implica em mudança de postura no processo de ensino-aprendizagem, que envolve atitudes e habilidades sociais amparadas na colaboração e nas habilidades de trabalho em rede. Mais ainda, o uso adequado dos recursos informacionais e midiáticos pelos indivíduos, especialmente para as tecnologias digitais, pode possibilitar aumento da confiança, do engajamento e de ideias que os motivem a serem agentes de mudança nesse novo contexto.

Ser aprendiz pleno, autônomo e reflexivo constitui-se missão crucial em uma sociedade com sobrecarga de informações. O papel da escola, como espaço de formação de cidadãos, deve abranger a importância do Letramento Informacional e Midiático (LIM) no ambiente acadêmico, tanto para os estudantes quanto para os professores, pois estes últimos são personagens-chave para o desenvolvimento do LIM tanto dentro quanto fora de sala de aula.

É possível perceber que as interfaces tecnológicas, especialmente a internet (web), não atuam apenas como transporte da informação, mas interferem na condição da própria informação nos aspectos da percepção, disseminação, reprodução e interação. Jorente (2012, p. 89) afirma que a "[...] Web 2.0 representa participação, coletivismo, comunidades virtuais, amadorismo, em que receptores passivos dos mass media passaram a interagentes produtores de informação.”, e isso endossa o que Jenkins (2009) afirma sobre convergência, inteligência coletiva e participação: os três pilares do paradigma social atual.

A informação e mídia são completamente convergentes no cenário social atual de cibercultura, o qual potencializa o compartilhamento, a distribuição, a cooperação e a apropriação das informações. Ao contrário das mídias "tradicionais", que permitiam o consumo de informação de forma unilateral e igual (broadcasting), a internet (web) permite protagonismo, aprendizagem 
independente, colaboração, conectivismo e hibridização dos meios e das linguagens (JORENTE, 2012).

$\mathrm{O}$ ato de aprender, por natureza, é uma experiência multimídia (HEPWORTH; WALTON, 2009), portanto separar o contexto de aprendizagem das plataformas de mídias se torna tarefa sem consistência e desalinhada da maneira como as pessoas aprendem. $\mathrm{Na}$ atual conjuntura, a experiência de aprendizagem midiática tem se constituído cada vez mais cedo na vida dos indivíduos.

De acordo com Belloni (2012, p. 33), “[...] mídia-educação significa, antes de mais nada, falar a linguagem dos alunos, usar os meios de comunicação para criar condições ótimas de ensino e priorizar a comunicação sobre os padrões escolares.”. Buckingham (2003) especifica a mídia-educação como o processo de ensinar e aprender sobre as mídias e o letramento midiático como o resultado - as habilidades e conhecimentos adquiridos pelos aprendizes, que envolvem a "leitura" e a "escrita" crítica da mídia e participação ativa nesses meios.

A UNESCO ${ }^{2}$ aborda o letramento informacional e midiático em uma perspectiva integrada, como se observa no documento intitulado Alfabetização Midiática e Informacional: Currículo para Formação de Professores (WILSON et al., 2013). No referido documento, a UNESCO entende que a alfabetização informacional, neste artigo denominada Letramento Informacional, constitui-se fator importante para o acesso à informação e a avaliação do uso ético da informação. A alfabetização midiática, neste artigo denominada Letramento Midiático, enfatiza a capacidade de compreender as funções da mídia, de avaliar como as funções são desempenhadas e de engajar-se conscientemente às mídias com o propósito de exercer os direitos, especialmente aqueles expressos no Artigo 19 da Declaração Universal dos Direitos Humanos, que versa sobre a liberdade de expressão.

Na matriz proposta pela UNESCO (WILSON et al., 2013), há três áreas temáticas centrais que se interrelacionam: 
a) o conhecimento e a compreensão das mídias e da informação para os discursos democráticos e para a participação social;

b) a avaliação dos textos de mídia e das fontes de informação;

c) a produção e o uso das mídias e da informação.

Ao se considerar a sociedade em rede (CASTELLS; CARDOSO, 2005) e o novo contexto da aprendizagem, o letramento informacional e midiático torna-se componente fundamental na formação docente. A formação constitui-se em um conjunto de conhecimentos, ações e atitudes que possibilitam o fazer pedagógico do professor em sala de aula (GASQUE, 2003).

A produção de conteúdo e o uso das mídias no contexto escolar por meio de uma pedagogia centrada no aprender fazendo,

[...] estimula a investigação e o pensamento reflexivo por parte dos estudantes. A aprendizagem prática é um importante aspecto da assimilação de conhecimento no século XXI [...] Os professores devem desempenhar um papel ativo nesse processo. (WILSON et al., 2013, p. 28).

\section{Formação de professores no século XXI}

A formação dos professores enfrenta tempos de mudanças para se adaptar ao novo contexto de aprendizagem. Kenski (2013) afirma que os novos tempos levam à necessidade de revisão crítica e reorientação da escola, da ação dos professores e dos modos como esses aspectos são operacionalizados.

Imbernón (2001) ao traçar evolução histórica sobre a formação dos professores, afirma que foi nos anos 2000 que surgiu uma crise profunda na profissão docente, devido a nova economia globalizada, popularização das tecnologias digitais e consolidação da internet. $\mathrm{O}$ autor enfatiza que os sistemas anteriores não funcionam mais, a arquitetura antiga das instituições de ensino não é mais adequada para as novas formas de educação, mais participativa, colaborativa e protagonista.

Para Mosé (2013), o aprender contemporâneo deve estar vinculado ao criar. Aprender criando é a regra, porque o contrário disso é apenas treinamento, pois não há troca, há imposição. Lévy (2007) apresenta algumas constatações a 


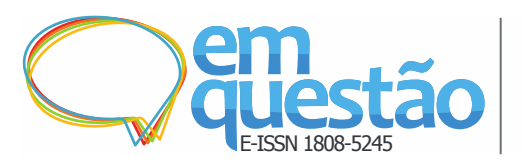

respeito dessa mudança de direção e do desejo por uma aprendizagem mais inovadora:

a) velocidade de surgimento e de renovação de saberes - pela primeira vez na história da humanidade, a maioria das competências adquiridas por uma pessoa no início do percurso profissional estará obsoleta no fim da carreira;

b) nova natureza do trabalho - constatação fortemente ligada à primeira, diz respeito a transação de conhecimentos que não para de crescer. Trabalhar significa aprender, transmitir saberes e produzir conhecimento;

c) tecnologias intelectuais - o ciberespaço suporta tecnologias intelectuais que amplificam, exteriorizam e modificam numerosas funções cognitivas humanas: memória (banco de dados, hiperdocumentos, arquivos digitais de todos os tipos), imaginação (simulações), percepção (sensores digitais, telepresença, realidades visuais), raciocínios (inteligência artificial, modelização de fenômenos complexos).

Por isso, é preciso inserir o professor em um contexto de experimentação para que ele possa se apropriar do novo contexto de aprendizagem transformado pela Geração Internet (TAPSCOTT, 2010). Sobre isso, Dudziak (2005) ressalta que a formação de professores para informação requer repensar crenças e práticas. Além disso, deve-se partir para a ação que priorize a atitude de pesquisa, de autonomia crítica e a busca criativa de informações que gerem novos conhecimentos.

Silva Neto (2014) enfatiza a formação dos docentes para tecnologias alinhadas com a competências em informação ao afirmar que a preparação do professor frente ao uso dessas tecnologias por meio de diretrizes educacionais é componente fundamental na educação e, principalmente, na excelência na busca pela informação. Ressalta-se que a inserção digital consta no Plano Nacional de Educação (PNE) 2011-2020 (BRASIL, 2010), que prevê a universalização do acesso a Internet em formato banda larga de alta velocidade e o aumento da relação computadores/estudante nas escolas da rede pública de educação básica, promovendo a utilização pedagógica das tecnologias digitais. 
Apesar de haver mais cursos de formação de professores e preocupação com as inovação, Imbernón (2012) observa que há pouca transformação na prática dos professores. Destaca que a maioria dos cursos de formação são mais teóricos e servem para promover a atualização de um tema ou conteúdo. Ao contrário disso, precisa-se ter coragem para pensar em novos modelos de formação dos professores, os quais, segundo Imbernón (2012), Lacerda Santos (2003), Kenski (2013) e Gabriel (2013), devem privilegiar:

a) o resgate à curiosidade e a criatividade, pois são fatores que geram a inovação;

b) a ideia de formação colaborativa e não individualista para que os professores aprendam a trabalhar em uma perspectiva globalizante;

c) a formação de professores protagonistas, autores e sensíveis para a produção de conhecimento em prol da comunidade;

d) o desenvolvimento de habilidades e competências emocionais e informacionais;

e) a melhoria nas políticas públicas que, por vezes, criam barreiras institucionais para a transformação da educação (vestibular, currículo extenso e não flexível, conteúdos seguimentos em disciplinas, entre outros).

Esses aspectos da busca por uma nova formação de professores reforçam a afirmação de Gabriel (2013) ao argumentar que o professor deve deixar de ser informador para ser formador. Caso contrário, o uso da tecnologia terá apenas aparência de modernidade. Além disso, a autora chama a atenção ao fato que o advento da internet e das novas tecnologias digitais, a "Era da Informação" tem se transformado gradativamente para a "Era da Interface". A informação hoje tem se tornado, de algum modo, disponível a todos, mas só consegue ser acessada de modo inteligível por intermédio de filtros, que são as interfaces.

Propiciar cursos de formação inicial e/ ou continuada centrado no professor como interface possibilita compreender que o novo contexto de aprendizagem deve centrar-se na formação informacional e midiática dos estudantes. Isso é o que cada vez mais fará a diferença no cidadão/profissional 
de hoje: saber discernir sobre o que as tecnologias representam em nossas vidas na sociedade em rede, "[...] como nos afetam e como extrair conhecimento e inteligência do ambiente hiperinformacional por meio dessas tecnologias." (GABRIEL, 2013, p. 127).

Gasque (2008) afirma que a implementação de processos e atividades que privilegiem o uso do pensamento reflexivo, de maneira contínua, possui grande potencial para promover educação transformadora. Isso porque a abordagem reflexiva considera a experiência dos aprendizes, dos professores e da própria comunidade, o que leva a uma educação emancipatória, autônoma, responsável e ética. Desta forma, a escola não seria a preparação para a vida, mas a própria vida, como defende Dewey (1979), a partir do que ele intitulou de pedagogia de projetos.

Em sintonia com essa proposta, emerge o movimento maker, também conhecido como movimento de "fazedores". O movimento, conforme Martinez e Stager (2013) surgiu como representante da esperança para a educação progressista no berço do Instituto de Tecnologia de Massachusetts (MIT) e nos centros de tecnologias no Vale do Silício nos Estados Unidos. Um dos pensadores foi Piaget (1896 - 1980), o qual também foi um dos defensores das ideias de Dewey (1859 - 1952). Os autores rejeitavam fortemente a educação regimentada pelos modelos de fábrica advindos da revolução industrial e advogavam por uma educação que preparasse crianças para resolver problemas a partir das próprias experiências.

Gasque (2008) argumenta que o pensamento reflexivo de Dewey é um potencializador do Letramento Informacional. O movimento maker surge como estratégia alternativa para o desenvolvimento do pensamento reflexivo. Nesse movimento, o papel do professor consiste em ensinar o aprendiz a buscar as informações, avaliá-las e usá-las para tomar decisões.

Portanto, para buscar, usar informações e agir pedagogicamente nesse cenário, os professores precisam construir e desenvolver competências informacionais e midiáticas que podem ser mais eficazes mediante o emprego do pensamento reflexivo (GASQUE, 2008), por meio de formações docentes que estimulem esse tipo de pensamento, como o "aprender fazendo" (maker). 
Nessa perspectiva, torna-se importante levantar estudos e pesquisas que permitam compreender melhor o contexto em que ocorrem processos de formação inovadores por meio do letramento informacional e midiático.

\section{Pesquisas sobre formação de professores no Letramento Informacional e Midiático}

O tópico de estudos sobre letramento informacional e midiático mostra avanços significativos. Entretanto, ao buscar por essas pesquisas é possível verificar que ainda são produzidas com pouca ou quase nenhuma interface entre as áreas. Em outras palavras, as pesquisas que envolvem o letramento de professores tanto na parte informacional quanto na parte midiática (também denominada letramento digital) nem sempre dialogam, apesar de haver caminhos de interseção entre as duas áreas.

Com o objetivo de levantar trabalhos científicos na área de letramento informacional e midiático com o foco no professor no Brasil foram utilizados os critérios de busca:

a) pesquisas mais relevantes por ordem de atualização (de 2010 a 2014);

b) uso de diversos bancos de dados tais como Education Resources Information Center (ERIC), Portal Capes, Scielo, bibliotecas digitais de universidades internacionais e nacionais, entre outros;

c) uso de palavras-chave relacionadas com o tema de letramento informacional e midiático para professores, tais como alfabetização informacional e letramento digital;

d) delimitação das pesquisas no âmbito da formação de professores para a educação básica;

e) delimitação das pesquisas por país (Brasil).

O levantamento foi realizado no segundo trimestre de 2014. Identificaram-se que as pesquisas de letramento informacional que envolvem o docente da educação básica no Brasil, em sua maior parte, centram-se no bibliotecário em novos papéis como o de educador. Quando há o foco no 
professor, geralmente está associado ao professor dos cursos de graduação e pós-graduação em biblioteconomia ou tecnologias.

Destacam-se aqui, portanto, o registro de três pesquisas no Brasil sobre letramento/competência em informação e formação do professor a partir dos critérios de busca elencados anteriormente. Uma delas, apesar de não tratar especificamente da formação de professor, inclui o tópico como essencial para implementar programas de LI na educação básica. As pesquisas são apresentadas a seguir:

a) Inclusão digital e competência informacional no contexto da alfabetização em séries iniciais por Machado, Santos e Araújo (2014) - essa pesquisa qualitativa ocorreu nas séries iniciais e os sujeitos de pesquisa foram estudantes dessa etapa escolar, juntamente com o professor de informática da escola e a coordenadora. O objetivo foi analisar a percepção dos participantes sobre a importância do letramento informacional e digital no ambiente escolar;

b) Desafios para implementar o letramento informacional na educação básica por Gasque e Tescarolo (2010) - levantamento sobre os desafios para se colocar plenamente em prática o letramento informacional na educação básica. $O$ estudo não tem o foco exclusivo no professor, mas sim centra-se no sistema educacional. Algumas soluções foram propostas para superar tais desafios;

c) Competências em informação para inclusão digital: os professores da educação básica na sociedade em rede por Silva Neto (2014) investigação sobre as competências em informação no processo formativo no Programa Nacional de Formação Continuada em Tecnologia Educacional (PROINFO). Descreve as ações da competência para a inclusão digital de professores no contexto do PROINFO, além disso, o pesquisador elaborou e aplicou modelo de ação para criação de oficinas voltadas ao desenvolvimento dessas 
competências para professores da rede municipal da Cidade de João Pessoa (Paraíba, Brasil).

Ao contrário das pesquisas realizadas sobre letramento informacional na área de educação de professores no nível básico no Brasil, os trabalhos científicos sobre letramento midiático/digital e a formação docente nacionais têm bastante tradição (desde a metade do século $\mathrm{XX}$ ), com grande variedade e em franca ampliação (BELLONI, 2012). Dos trabalhos recuperados, apresentam-se os três mais relevantes para a presente pesquisa, quais sejam:

a) Letramento digital e formação de professores por Freitas (2010) - o estudo apresenta definições de letramento digital que refletem os desafios postos à escola pelo confronto com as novas práticas de leitura e escrita propiciadas pelos usos do computador e da internet. Em seguida, analisa a formação do professor para a inserção das tecnologias nas práticas pedagógicas e para compreenderem o letramento digital dos alunos.

b) Práticas de letramento digital de professores em formação: demandas, saberes e impactos por Câmara (2013) - o objetivo foi investigar as práticas de letramento digital de 38 professores em formação, inicial e continuada, em três momentos específicos: antes, durante a após a realização de uma ação de curso de extensão. A análise dos dados permitiu evidenciar que (i) antes do curso, as práticas de letramento digital dos professores concentravam-se nas dimensões pessoal e acadêmica de suas realidades, em detrimento da dimensão profissional; (ii) durante a ação de extensão, os professores participaram, de modo colaborativo, das sessões de estudo semipresenciais com foco no uso pedagógico das tecnologias digitais, efetivando práticas de letramento digital até então desconhecidas; (iii) após o curso, a postura dos professores diante da utilização das tecnologias digitais no cotidiano profissional sofreu modificações. Os docentes passaram a utilizá-las efetivamente, dando visibilidade social ao que é produzido na escola. Foi observado, ainda, que os professores em formação inicial atuaram 
como pares mais experientes no processo de aprendizagem colaborativa para os professores em formação continuada. Isso ocorreu em razão de os graduandos efetivarem práticas de letramento digital mais sofisticadas, por integrarem a chamada geração Y.

c) Letramento digital: uma abordagem através das competências na formação docente por Ribeiro (2013) - o objetivo da pesquisa foi identificar os aspectos determinantes para a construção de conhecimentos, habilidades e atitudes necessárias para o desenvolvimento de competências no letramento digital. Dessa forma, foram mapeadas as competências com potencial para contribuir para o letramento digital de professores da Educação Básica e observados os aspectos que influenciam no desenvolvimento das habilidades digitais. Entre as competências mapeadas, destacaram-se a competência informacional, a multimídia, e computacional e a comunicacional.

Após as pesquisas sobre aspectos da formação docente na educação básica no Brasil, examinadas pelo prisma do letramento informacional e midiático, observou-se que ainda os investimentos ainda são tímidos em termos de quantidade de investigações que integram os dois letramentos, além de verificar a alta incidência de pesquisas centradas na instrumentalização do professor no letramento informacional e midiático.

Nesse sentido, a literatura mostra a necessidade de avançar na abrangência dos campos de pesquisa e delinear novas questões, tais como: a maneira como o professor aprende; como o professor se percebe como aprendiz ao longo da vida; o professor como aprendiz, protagonista e independente no processo de aprendizagem; como o professor busca as informações e as transforma em conhecimento para levar até a sala de aula; a compreensão e o uso das novas formas de se aprender na contemporaneidade. Além da necessidade de que as pesquisas, informacional e midiática, dialoguem-se entre sim, pois uma está evidenciada na outra. 


\section{Conclusão}

Vários pesquisadores e instituições da CI (ASSOCIATION OF COLLEGE..., 2000; CAMPELO, 2003; DUDZIAK, 2003; HEPWORTH; WALTON, 2009; GASQUE, 2010) demonstram em seus trabalhos a importância da educação por meio do Letramento Informacional. Afirmam que o desenvolvimento das competências em informação são fundamentais para melhorar a busca, o uso e o compartilhamento da informação, corroborando para o desenvolvimento responsável e sustentável da informação na sociedade.

Observar o meio em que a informação é vinculada também é importante no processo de aprendizagem, pois, historicamente, a evolução das tecnologias da informação e comunicação mostra como o fluxo informacional modificou as concepções e modelos de comunicação de ensino- aprendizagem na sociedade.

É, pois, preciso compreender melhor sobre a localização e o acesso às informações, em quais mídias são disseminadas, onde e como as pessoas buscam essas fontes para construção do conhecimentos, bem como desenvolver visão crítica para a mídia divulgada pelas agências de publicidades. Portanto, estudar, compreender e analisar as tecnologias e a informação tornam-se também essenciais para o desenvolvimento da pedagogia contemporânea, a qual tem sido objeto de estudo em variadas áreas do conhecimento, ao perceber o fenômeno do ensino-aprendizagem como complexo e interdisciplinar.

Por sua vez, o docente precisa saber como lidar com as informações nos vários suportes midiáticos para ensinar. Conhecer e pesquisar sobre essa área do conhecimento, especialmente na formação continuada, torna-se fundamental para que a pedagogia contemporânea ocorra de maneira efetiva. Além disso, propicia caminho de qualidade e de sustentabilidade da informação e da produção do conhecimento, que abrange a busca e uso do informação, uma vez que as escolas formam cidadãos que pertencem e produzem para a sociedade em rede.

Assim, é preciso oferecer cursos de formação continuada direcionada para o Letramento Informacional e Midiático para os professores. Os cursos devem ter por base estratégias que levem à prática do pensamento reflexivo e a 
vivência de experiências. O movimento maker se mostra como potencializador desse tipo de formação, pois tem por natureza características de criatividade, inovação e autoria por meio do "aprender fazendo", que Dewey (1979) advogava como requisitos importantes para o desenvolvimento do pensamento reflexivo.

Sendo assim, esse cenário de mudanças para um modelo de educação XXI na formação dos professores mostra-se bastante interessante para os cientistas da informação, especialmente os que seguem a linha do letramento informacional, de forma que podem repensar em novos formatos de programas de formação de professores para a implementação do letramento informacional e midiático na educação.

\section{Referências}

ASSOCIATION OF COLLEGE AND RESEARCH LIBRARY. Information literacy competency for higher education. Chicago: ALA, 2000. Disponível em: 〈http://www.ala.org/acrl/standards/informationliteracycompetency〉. Acesso em: 3 set. de 2014.

BELLONI, M. L. Mídia-Educação: contextos, histórias e interrogações. In: FANTIN, M.; RIVOLTELLA (Org.) Cultura digital e escola: pesquisa e formação de professores. Campinas: Papirus, 2012.

BRASIL. Congresso Nacional. Projeto de Lei. Plano Nacional de Educação para o decênio 2011-2020. Brasília, 2010. Disponível em:

$<$ http://portal.mec.gov.br/index.php?option=com docman\&task=doc download

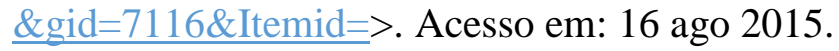

BOEKHORST, A.K. (M)IL and its Kind. In: CONFERENCE OF THE MEDIA AND INFORMATION LITERACY FOR KNOWLEDGE SOCIETY, 2012, Moscow (Russia). Anais eletrônicos.... Moscow: Interregional Library Cooperation Centre, 2013. 432 p. Dispon;ivel em: http://www.ifapcom.ru/files/News/Images/2013/mil_eng web.pdf> . Acesso em: 16 ago. 2015.

BUCKINGHAM, D. Media education: literacy, learning, and contemporary culture. Cambridge: Blackwell, 2003. 
CÂMARA, Louize Lidiane Lima de Moura. Práticas de letramento digital de professores em formação: demandas, saberes e impactos. 2013. $270 \mathrm{f}$.

Dissertação (Mestrado em Linguística Aplicada; Literatura Comparada) Universidade Federal do Rio Grande do Norte, Natal, 2013.

CAMPELO, B. S. O movimento da competência informacional: uma perspectiva para o letramento informacional. Revista Ciência da Informação, Brasília, v. 32, n. 3, p. 28-37, set./dez. 2003. Disponível em:

<http://marista.edu.br/bibliotecas/files/2010/03/o-movimento-da-competenciainformacional1.pdf>. Acesso em: 8 out. 2014.

CASTELLS, M.: CARDOSO, G. (Org.) Sociedade em rede: do conhecimento à acção política. Belém: Imprensa Nacional, Casa da Moeda, 2005. Disponível em:

<http://www.egov.ufsc.br/portal/sites/default/files/anexos/a_sociedade_em_rede ___do_conhecimento_a_acao_politica.pdf). Acesso em: 10 de set 2014.

COMMISSION OF THE EUROPEAN COMMUNITIES. A European approach to media literacy in the digital environment. Brussels, 2007. Disponível em:

<http://www.cedefop.europa.eu/en/news-and-press/news/european-approachmedia-literacy-digital-environment>. Acesso em: 16 ago. 2015.

DEWEY, J. Como pensamos: como se relaciona o pensamento reflexivo com o processo educativo, uma reexposição. 4. ed. São Paulo: Nacional, 1979.

DUDZIAK, E. A. Competência em Informação: melhores práticas educacionais voltadas para a Information Literacy. In: CONGRESSO BRASILEIRO DE BIBLIOTECONOMIA, DOCUMENTAÇÃO E CIÊNCIA DA

INFORMAÇÃO, 21., 2005, Curitiba. Anais... Curitiba: FEBAB, 2005.

DUDZIAK, E. A. Information Literacy: princípios, filosofia e prática. Revista Ciência da Informação, Brasília, v. 32, n. 1, p. 23-35, jan/abr. 2003. Disponível em: <http:// revista.ibict.br/ciinf/index.php/ciinf/article/ view/123/104>. Acesso em: 15 set. 2014.

FREITAS, M. T. Letramento digital e formação de professores. Educação em Revista, v. 26, n. 3, p. 335-352, Belo Horizonte, dez. 2010. Disponível em <http://www.scielo.br/pdf/edur/v26n3/v26n3a17> . Acesso em: 8 out. 2014.

GABRIEL, M. Educ@r: a revolução digital na educação. São Paulo: Saraiva, 2013.

GASQUE, K. C. G. D.; TESCAROLO, R. Desafios para implementar o letramento informacional na educação básica. Educação em Revista, v. 26, n. 1, p. 41-56, Abr. Belo Horizonte, 2010. Disponível em:

<http://www.scielo.br/pdf/edur/v26n1/03.pdf>. Acesso em: 10 out. 2014. 
GASQUE, K. C. G. D. A. O pensamento reflexivo na busca e no uso da informação na comunicação científica. 2008. Tese (Doutorado em Ciência da Informação) - Faculdade de Ciência da Informação, Universidade de Brasília, Brasília, 2008.

GASQUE, K. C. G. D.; COSTA, S. M. S. Comportamento dos professores da educação básica na busca da informação para formação continuada. Ciência da Informação, Brasília , v. 32, n. 3, 2003. Disponível em:

$<$ http://www.scielo.br/scielo.php?script=sci_arttext\&pid=S010019652003000300007\&lng=en\&nrm=iso>. Acesso em: 21 nov. 2014.

HEPWORTH, M.; WALTON, G. Teaching Informagion Literacy for Inquiry-Based Learning. [S.1.]: Chandos, 2009.

IMBERNÓN, F. Claves para una nueva formación del professorado. Revista Investigación em la escuela, n. 43, p. 57-66, 2001. Disponível em: $<$ http://dialnet.unirioja.es/servlet/articulo?codigo=117059>. Acesso em: $13 \mathrm{de}$ out 2014.

IMBERNÓN, F. Formação permanente e carreira docente. Revista de Ciências Humanas v. 13, n. 20, p. 45-50, jun. 2012. Disponível em:

<http://revistas.fw.uri.br/index.php/revistadech/article/viewFile/352/637 >. Acesso em: 10 out. 2014.

JENKINS, H. Cultura da convergência. 2. ed. São Paulo: Aleph, 2009. Disponível em: < http://www.editoraaleph.com.br/site/media/catalog/product/f/i/file_1.pdfl $>$. Acesso em: 16 ago 2015.

JORENTE, M. J. V. Ciência da Informação: mídia e convergência de linguagens na Web. São Paulo: Cultura Acadêmica, 2012.

KENSKI, V. M. Tecnologias e tempo docente. Campinas: Papirus, 2013.

KURBANOGLU, Serap. An Analysis of the Concept of Information Literacy. In: CONFERENCE OF THE MEDIA AND INFORMATION LITERACY FOR KNOWLEDGE SOCIETY, 2012, Moscow (Russia). Anais eletrônicos.... Moscow: Interregional Library Cooperation Centre, 2013. 432 p. Dispon;ivel em: http://www.ifapcom.ru/files/News/Images/2013/mil_eng web.pdf> . Acesso em: 16 ago. 2015.

LACERDA SANTOS, G. A internet na escola fundamental: sondagem de modos de uso por professores. Revista Educação e Pesquisa, São Paulo, v. 29, n. 2, 2003. Disponível em: <http://www.scielo.br/scielo.php?pid=S1517$97022003000200008 \&$ script=sci arttext $>$. Acesso em: 5 out. 2014.

LEE, A.Y.L.; SO, C.Y.K. Media Literacy and Information Literacy: Similarities and Differences.. Comunicar, v. 42, p. 137 -146, 2014. 
LÉVY, P. Cibercultura. Tradução de Carlos da Costa. São Paulo: Editora 34, 1999.

LÉVY, P. O que é virtual. Tradução de Paulo Neves. São Paulo: Editora 34, 2007.

MACHADO, A. M. F.; SANTOS, T. C. M.; ARAÚJO, R. F. Inclusão digital e competência informacional no contexto da alfabetização em séries iniciais. Ciência da Informação em Revista, v. 1, n. 2, p. 32-41, maio/ago, 2014. Disponível em: 〈http://www.seer.ufal.br/index.php/cir/article/view/1321〉. Acesso em: 12 nov. 2014.

MARTINEZ, S. L.; STAGER, G. Invent to learn: making, tinkering, and engineering in the classroom. [S.1.]: Construct in Modern Knowledge, 2013.

MOSÉ, V. A escola e os desafios contemporâneos. Rio de Janeiro: Civilização Brasileira, 2013.

RIBEIRO, A. C. R. Letramento digital: uma abordagem através das competências na formação docente. 2013. Dissertação (Mestrado em Educação) - Programa de Pós-Graduação em Educação da Universidade Federal do Rio Grande do Sul, Porto Alegre, 2013. Disponível em:

<http://www.lume.ufrgs.br/handle/10183/72140> . Acesso em: 27 out. 2014.

SANTAELLA, L. Pós-humano, por quê? Revista USP, São Paulo, n. 74, p. 126-137, jun./ago. 2007.

SILVA NETO, C. E. Competências em Informação para Inclusão Digital: os professores da educação básica na sociedade em rede. 2014. Dissertação (Mestrado em Ciência da Informação) - Programa de Pós-Graduação em Ciência da Informação, Universidade Federal da Paraíba, João Pessoa, 2014.

TAKAHASHI, T. Sociedade da informação: livro verde. Brasília: Ministério da Ciência e Tecnologia, 2000. Disponível em:

<http://www.mct.gov.br/upd_blob/0004/4795.pdf>. Acesso em: 8 jul. 2015.

TAPSCOTT, D. A hora da geração digital: como os jovens que cresceram usando a internet estão mudando tudo, das empresas aos governos. Tradução: Marcello Lino. Rio de Janeiro: Agir Negócios, 2010.

WILSON, C. et al. Alfabetização midiática e informacional: currículo para formação de professores. Brasília: UNESCO, 2013. 


\title{
Information and Media Literacy for teachers who teach in the
}

\section{1st century}

\begin{abstract}
The actual society has been passing through deep changes in its organized structure since it has functioned as a network system in a digital connected world. The systemic transformation changed the process of all over society, and, in special, the education area. This article foster the discussion about teachers' education in the 21 st century through out the contemporary learning context, the relation between teachers and media and, also presents a sample of research about information and media literacy for teachers' education. The results show few researches about teachers' education and the information literacy. The most part focused in the librarian in his/her rule as educator or when there is the focus in the teacher, they are often linked to teachers who work with the librarianship or technologies. The opposite of it happens in the research of media literacy and teachers' education, which has a large tradition work in the area (since the middle of the 20th century) that continues grows.
\end{abstract}

Keywords: Information Literacy. Media Literacy. Teachers' education. Education for 21 st century.

\footnotetext{
${ }^{1}$ Palestra proferida por Martha Gabriel no evento sobre cultura de internet YouPix, em agosto de 2011. Disponível em;<http://youpix.virgula.uol.com.br/festival/youpix-na-integra-cibridismo-o-fim-do-mundooffline-19ago2011/>. Acesso em: 9 nov. 2014.

2 Alguns autores consideram o letramento midiático como área de estudo distinta do letramento informacional, por exemplo, Lee e So, (2014); Comissão Europeia (COMMISSION OF THE EUROPEAN..., 2007), dentre outros. Destaca-se que a Comissão Europeia em seus documentos trata da importância do desenvolvimento do pensamento crítico voltado para os meios de comunicação comercial. Este aspecto é uma das características distintivas do letramento mediático que não pode ser encontrada em outro letramento. Por outro lado, muitos pesquisadores da ciência da informação percebem o letramento informacional como área mais ampla que engloba o letramento midiático (BOEKHORST, 2013; KURBANOGLU 2013). Apesar da importância da discussão sobre o assunto, a questão terminológica não é o foco desse artigo.
} 
Letramento Informacional e Midiático para professores do século XXI

Leila Alves Medeiros Ribeiro, Kelley Cristine Gonçalves Dias Gasque

Recebido: 26/11/2014

Aceito: 15/06/2015 